\title{
Familiality of depression in the community; associations with gender and phenotype of major depressive disorder
}

\author{
J. G. E. Janzing $\cdot$ R. de Graaf $\cdot$ M. ten Have $\cdot$ \\ W. A. Vollebergh $\cdot$ M. Verhagen $\cdot$ J. K. Buitelaar
}

Received: 8 December 2007/ Accepted: 24 February 2009/Published online: 25 March 2009

(C) The Author(s) 2009. This article is published with open access at Springerlink.com

\begin{abstract}
Introduction Although associations between family history and depression have been shown in clinical patients, it is unknown if they also apply to subjects living in the community. The present study considers the relationship between family loading and depression phenotype characteristics in a large community-based sample.

Method In a Dutch representative population sample of 7,076 individuals, lifetime diagnosis of depression was classified according to severity, course and age of onset. A family loading score of depression (FLSD) was computed by taking the proportion of the first-degree relatives for whom a history of depression was reported.

Results There was a strong association between FLSD and lifetime diagnosis of MDD. Severity, recurrence and early onset of depression were the specific phenotypic characteristics associated with familiality. The effects of FLSD and gender were independent.

Conclusion Associations between family history and risk for depression in the community confirm those reported from clinical-based studies using direct interviewing of relatives. A stronger degree of familiality is associated with specific phenotypic characteristics of depression.
\end{abstract}

J. G. E. Janzing $(\varangle) \cdot$ M. Verhagen · J. K. Buitelaar Department of Psychiatry, Radboud University Nijmegen Medical Centre, P.O. Box 9101, 6500 HB Nijmegen, The Netherlands

e-mail: j.janzing@psy.umcn.nl

R. de Graaf - M. ten Have · W. A. Vollebergh

Netherlands Institute of Mental Health and Addiction

(Trimbos Institute), Utrecht, The Netherlands

W. A. Vollebergh

Department of Social Sciences, Faculty of Social Sciences,

University of Utrecht, Utrecht, The Netherlands
Keywords Depressive disorder · Family history · Genetics · Gender · Community sample

\section{Introduction}

An increased liability for depression has been shown in family members of depressed probands [10, 22, 38]. According to a recent meta-analysis [36], the first-degree relatives of probands with major depressive disorder (MDD) have a two to threefold higher lifetime risk for depression compared to relatives of controls without depression. Although odds ratios are consistent across studies, a number of basic questions remain to be answered.

First, as most studies were on clinical patients, it is unclear to what extent findings can be generalized to subjects living in the community. Since depressed subjects from families with multiple cases of depression may be clinically referred easier than depressed subjects without a strong family-genetic loading, a focus on clinically referred patients and their relatives may lead to overestimation of family-genetic risks. Second, for analyses, familiality of depression has mostly been operationalized as a dichotomous variable, i.e. a family history was concluded to be positive or negative. A more differentiated picture may emerge when the degree to which depression runs into families has been taken into account. This allows one to further examine whether very strong degrees of familygenetic risk are associated with increased risk for depression, when compared to intermediate and very low levels of family-genetic risk. Third, more attention has to be paid to the role of gender. The recent finding of higher rates of MDD in female relatives than in male relatives of female adolescent probands and of comparable rates of MDD in female and male relatives of male probands may indicate 
sex specific transmission of depression [22]. According to a genome-wide linkage survey, sex specific genetic loci seem to play a role in the aetiology of depression [45]. Finally, as also Sullivan et al. [36] conclude, there is only little systematic evidence to what extent family history of depression is reflected in specific phenotypical characteristics in the proband. So far, early onset recurrent depression has been identified as the subtype with the potentially strongest heritable component $[24,45]$. Answers to the above mentioned issues will be helpful to improve the discrimination of depression phenotypes that more specifically mediate genetic influences. This will increase insight into the origin of depression and may finally result into more differentiated preventive and therapeutic strategies.

The main purpose of the present study is to examine if the associations between family history and risk for depression, that have been reported from clinical studies can be replicated in a representative community sample. The use of a dimensional measure of familiality allows taking into account the degree to which depression occurs in first degree family members. We hypothesize that familiality of depression is associated with specific phenotypical characteristics like severity, recurrence and early age of onset of depression. In addition to familiality, our study focuses explicitly on the role of gender in the pathogenesis of depression.

\section{Methods}

Sample

The data used for this study are part of the first wave of the Netherlands Mental Health Survey and Incidence Study (NEMESIS). The main aim of NEMESIS was to assess the prevalence of psychiatric disorders in a representative sample of the Dutch general population, aged 18-64 years. NEMESIS was approved by the ethics committee of the Netherlands Institute of Mental Health and Addiction, Utrecht, the Netherlands. The total baseline study sample consisted of 7,076 subjects which is equivalent with a $69.7 \%$ response rate. The sample followed the same multivariate distribution over age, sex, civil status and urbanity as the general Dutch population. Only the male 18-24 age group was slightly underrepresented. Item nonresponse was negligible as a result of the computerized interviewing. A detailed description of the study design and major outcomes has previously been published $[4,5]$.

\section{Composite International Diagnostic Interview}

The Composite International Diagnostic Interview (CIDI; version 1.1) $[34,44]$ was used for the assessment of DSM-
III-R Axis I disorders [1]. This instrument has been designed for use by trained interviewers who are not clinicians. The CIDI has acceptable inter-rater reliability [7], test-retest reliability [35] and validity for practically all diagnoses, including major depression [43].

Dependent variables

For the present study, only the lifetime diagnosis of MDD was considered. The following phenotypical characteristics were determined for subjects with MDD and were used as the main dependent variables in this study:

(a) Severity of depression was categorized into mild or moderate MDD versus severe MDD according to DSM-III-R diagnostic criteria. A total of 148 subjects reporting a lifetime diagnosis of depression $(2.1 \%$ of the total sample) could not be classified on this dimension as in these subjects the severity of depression was not specified.

(b) Course of depression was divided into the classes of MDD single episode and MDD recurrent according to DSM-III-R criteria.

(c) Based on the findings reported by Kendler et al. [17] that an age of onset of depression (AAO) after 35 years is associated with lower levels of familial depression compared to an earlier AAO we discriminated two classes: early AAO with first episode of depression occurring until the age of 35 years and late AAO with first episode occurring after age 35 years.

Independent variables

\section{Family loading score of depression (FLSD)}

Family history information was obtained by questioning subjects about the presence of psychiatric disorders in their first-degree relatives. Subjects were asked if their family members were ever hospitalized in a psychiatric setting, had received medical care for psychiatric disorders or ever had a psychiatric disorder.

Family history of depression was evaluated by asking the question: "did your...(insert the name of the first degree relative)... ever have a depression?" for every relative separately.

In an independent sample we compared family history based on this single question to a diagnosis according to Family History-Research Diagnostic Criteria (FH-RDC). The FH-RDC provides specific operational criteria for determining a family history diagnosis. It has excellent test-retest reliability and an acceptable level of validity compared to direct interviews [2]. In 323 relatives of 51 subjects we found substantial agreement between the single 
Table 1 Demographic characteristics, number of first degree relatives and family loading scores in the total sample $(n=7,076)$ by gender

\begin{tabular}{|c|c|c|c|c|}
\hline & Total $(n=7,076)$ & Women $(n=3,777)$ & $\operatorname{Men}(n=3,299)$ & Gender difference \\
\hline Age in years [mean $(\mathrm{SD})]$ & $41.2(12.2)$ & $41.2(12.4)$ & $41.1(12.0)$ & NS \\
\hline Level of education ${ }^{a}$ & & & & $\chi^{2}=92.5, p<0.001$ \\
\hline Low-intermediate & $45.1 \%$ & $50.5 \%$ & $39.0 \%$ & \\
\hline High & $54.9 \%$ & $49.5 \%$ & $61.0 \%$ & \\
\hline Total number of relatives ${ }^{\mathrm{b}}[$ mean $(\mathrm{SD})]$ & $5.3(2.6)$ & $5.3(2.6)$ & $5.3(2.6)$ & NS \\
\hline FLSD $^{\mathrm{c}}[$ median $(\mathrm{p} 25-\mathrm{p} 75)]$ & $0.00(0.00-0.17)$ & $0.00(0.00-0.17)$ & $0.00(0.00-0.13)$ & $U=5,826,849, p<0.001$ \\
\hline
\end{tabular}

FLSD family loading score for depression

${ }^{a}$ Low-intermediate education: primary, basic vocational and lower secondary level; high education level: higher secondary, higher professional level and university

b Total number of parents and siblings

${ }^{c}$ Mann-Whitney test. Effect size $r=-0.07$ (small)

question and the FH-RDC method $(\kappa=0.78)$. In a separate analysis we studied agreement between FH-RDC criteria and direct interviewing: in 40 out of 41 relatives (97.6\%) positive for depression according to FH-RDC criteria, a lifetime diagnosis of MDD according to DSM-IV criteria was confirmed by means of a CIDI-interview.

The family loading score of depression (FLSD) was defined as the proportion of the first-degree relatives (parents and siblings) for whom a lifetime history of depression was reported. For example, for a proband reporting one of her parents and two of her four siblings as positive for depression a FLSD of 3/6 or 0.5 was computed.

Only information regarding parents and siblings was included for computation of the FLSD. Information on the psychiatric status of children of probands was disregarded since a large proportion of the proband's children were prepubertal. As for the majority of people the first episode of depression occurs in or after adolescence [17] the inclusion of children would have contributed to an unjustified decrease of morbidity risks of first-degree relatives. Moreover, there is uncertainty if pre-pubertal depression shares the etiology of depression with first incidence in or after puberty [13].

\section{Potential confounders}

Educational attainment, in this study classified into lowintermediate level (primary, basic vocational and lower secondary education) and high level (higher secondary, higher professional and university), is a demographic factor that has been found to be associated with depression in community studies. In addition age is a potential confounder because the chance on a first depressive episode both in the proband and in the proband's relatives (expressed as FLSD) is dependent on age. In order to take effects of family size on FLSD into account the analyses are adjusted for the total number of first-degree relatives (including parents and siblings).
Statistical analysis

First, the relevant demographic characteristics and clinical characteristics of depression are presented and compared by proband gender (Tables 1,2). For the subgroup of probands with a lifetime diagnosis of MDD $(n=1145)$ interrelations of clinical characteristics were studied. $\chi^{2}$-analysis was used to compare categorical variables and the independent samples $t$ test and the Mann-Whitney test were used to compare continuous variables.

Multivariate logistic regression analyses were performed to investigate the effects of family loading and gender on depression in the total sample of probands (Table 3). The subsequent dependent variables were: overall lifetime diagnosis of depression, mild MDD, severe MDD, single episode MDD, recurrent MDD, MDD with early onset and MMD with late onset. The analyses were performed in four steps. In the first set of analyses (Table 3a) only the unadjusted effects of FLSD and proband gender (in these analyses we compared female gender with male gender serving as the reference category) were studied. In the second set (Table 3b) the effects of FLSD and proband gender were adjusted for the effects of potential confounders (age, educational level, and number of first-degree relatives). In the third set (Table 3c) we aimed to study if the effects of FLSD and gender on clinical characteristics were specific for the clinical characteristics expressed in the dependent variable. So in addition to potential confounders, these analyses were adjusted for the effects of other MDD characteristics (those not expressed in the dependent variable: for instance the analyses for recurrent MDD were adjusted for the effects of age of onset and severity). Finally we studied the effects of FLSD, proband's gender and the interaction between FLSD and proband's gender, adjusting for potential confounders.

We performed additional logistic regression analyses limited to the sample of probands with a lifetime diagnosis of depression in order to compare the effects of FLSD 
Table 2 Prevalences of phenotypical characteristics of lifetime diagnosis of major depressive disorder (overall diagnosis, severity, course and age of onset) presented in percentages of the total population $(n=7,076)$ including differences by gender

\begin{tabular}{|c|c|c|c|c|}
\hline & $\begin{array}{l}\text { Total }(n=7,076) \\
(\%)\end{array}$ & $\begin{array}{l}\text { Women }(n=3,777) \\
(\%)\end{array}$ & $\begin{array}{l}\text { Men }(n=3,299) \\
(\%)\end{array}$ & $\begin{array}{l}\text { Gender difference } \\
\text { (male as reference) }\end{array}$ \\
\hline Overall MDD & 16.2 & 20.5 & 11.2 & OR $2.0(1.8-2.3)$ \\
\hline \multicolumn{5}{|l|}{ Severity $^{\mathrm{a}}$} \\
\hline Mild & 8.6 & 10.1 & 6.9 & OR $1.5(1.3-1.8)$ \\
\hline Severe & 5.8 & 7.8 & 3.6 & OR $2.3(1.8-2.8)$ \\
\hline \multicolumn{5}{|l|}{ Course } \\
\hline Single episode & 10.0 & 12.0 & 7.6 & OR 1.7 (1.4-1.9) \\
\hline Recurrent & 6.2 & 8.5 & 3.6 & OR $2.5(2.0-3.1)$ \\
\hline \multicolumn{5}{|l|}{ Age of onset ${ }^{\mathrm{b}}$} \\
\hline Early & 11.5 & 15.4 & 7.1 & OR $2.3(2.0-2.8)$ \\
\hline Late & 4.7 & 5.1 & 4.2 & OR $1.2(1.0-1.6)$ \\
\hline
\end{tabular}

$M D D$ major depressive disorder

${ }^{\text {a }}$ For 148 subjects $(2.1 \%$ of the total sample) the severity of depression was not specified

b Early: age of onset from 0 to 35 years; Late: age of onset from 36 to 65 years

Table 3 Associations between risk factors (family loading, gender) and lifetime depression diagnosis by phenotypical characteristics

\begin{tabular}{llllllll}
\hline (a) Unadjusted analyses & & & & \\
\hline & MDD overall & MDD mild & MDD severe & MDD single & MDD recurr & Early AO $^{\text {a }}$ & Late AO $^{\text {b }}$ \\
\hline FLSD & $8.6(6.2-12.1)$ & $3.3(2.1-5.2)$ & $14.5(9.1-23.0)$ & $3.9(2.6-5.9)$ & $12.0(7.7-18.8)$ & $10.1(7.6-15.8)$ & $2.1(1.2-3.9)$ \\
Female gender $^{c}$ & $2.0(1.7-2.2)$ & $1.5(1.2-1.8)$ & $2.1(1.7-2.7)$ & $1.6(1.4-1.9)$ & $2.3(1.9-2.9)$ & $2.3(1.9-2.7)$ & $1.2(1.0-1.5)$
\end{tabular}

(b) Analyses adjusted for the effects of potential confounders (age, education level and number of first degree relatives)

\begin{tabular}{llllllll}
\hline & MDD overall & MDD mild & MDD severe & MDD single & MDD recurr & Early AO $^{\mathrm{a}}$ Late AO $^{\mathrm{b}}$ \\
\hline FLSD & $8.6(6.1-12.1)$ & $3.1(2.0-4.9)$ & $16.2(10.1-25.9)$ & $4.0(2.6-6.0)$ & $11.5(7.3-18.1)$ & $9.8(6.7-14.2)$ & $3.8(2.0-7.3)$ \\
Female gender $^{\mathrm{c}}$ & $2.0(1.7-2.2)$ & $1.5(1.3-1.8)$ & $2.1(1.7-2.6)$ & $1.6(1.3-1.9)$ & $2.4(1.9-3.0)$ & $2.3(2.0-2.7)$ & $1.2(0.9-1.5)$
\end{tabular}

(c) Analyses adjusted for the effects of potential confounders (age, education level and number of first degree relatives) and other depression characteristics

\begin{tabular}{llll}
\hline Depression characteristics adjusted for: & $\begin{array}{l}\text { MDD severe } \\
\text { Recurr, early AO }\end{array}$ & $\begin{array}{l}\text { MDD recurr } \\
\text { Severe, early AO }\end{array}$ & $\begin{array}{l}\text { Early AO }^{\mathrm{a}} \\
\text { Severe recurr }\end{array}$ \\
\hline FLSD & $6.4(3.6-11.5)$ & $3.2(1.8-5.8)$ & $3.5(2.1-5.7)$ \\
Female gender $^{c}$ & $1.4(1.1-1.9)$ & $1.5(1.2-2.0)$ & $1.9(1.5-2.3)$ \\
\hline
\end{tabular}

Results from logistic regression analysis for the total sample $(n=7076)$ [odds ratios $(95 \% \mathrm{CI})$ ]

$M D D$ major depressive disorder, $F L S D$ family loading score of depression, $A O$ age of onset first depressive episode

${ }^{a}$ Early age of onset: onset between 0 and 35 years

b Late age of onset: onset between 36 and 65 years

c Reference category: male gender

(independent variable) on contrasting clinical characteristics of depression (dependent variable): mild (reference category) versus severe depression, single episode (reference category) versus recurrent depression and late onset (reference category) versus early onset depression, respectively. These analyses were adjusted for the effects of gender, age, education and number of first-degree relatives.
Associations in logistic regression analyses were expressed as odds ratios (ORs) and 95\% confidence intervals $(95 \% \mathrm{CI})$. Differences between odds ratios can be considered statistically significant according to the criterion that the confidence intervals of a risk factor mutually exclude the point estimates in one or both of the other categories [9]. 


\section{Results}

Demographic characteristics and family loading

Table 1 shows the relevant demographic characteristics and family loading and compares figures for men and women. The total sample consisted of 3,777 women $(53.4 \%)$ and 3,299 men (46.6\%). Ages of men and women were similar. Men had significantly higher education levels than women: $60.9 \%$ of the men had high to very high education, compared to only $49.5 \%$ of the women. The overall number of first-degree relatives (parents and siblings) was equal for both sexes. Women reported a slightly higher FLSD compared to men (effect size $r=-0.07$ ).

\section{Clinical characteristics}

Table 2 shows the prevalences and gender differences in phenotypical characteristics of lifetime MDD in the probands. Overall, a diagnosis of MDD was reported about two times more frequently by women compared to men. All clinical subtypes of depression were more frequently observed for female probands: with limited gender differences for mild depression, single episode depression and late onset depression and with larger gender differences for severe depression, recurrent depression and early onset depression.

Associations between depression characteristics were studied in the subgroup of subjects who had reported a lifetime diagnosis of depression $(n=1145)$. There was no evidence of a significant relationship between course and severity of depression: from the subjects with mild depression 233 of 596 (39.1\%) had the recurrent subtype, from the subjects with severe depression this proportion was 154 of 401 (38.4\%; OR $1.095 \%$ CI 0.75-1.26). There was also no significant association between age of onset of depression and severity: 273 of 401 (68.1\%) subjects with severe depression had early onset compared to 434 of 596 (72.8\%) of the subjects with mild depression (OR $0.895 \%$ CI 0.6-1.1). However, course characteristics and age of first onset of depression were interrelated: 342 of 439 (77.9\%) subjects with recurrent depression had an early age of onset compared to 471 of $706(66.7 \%)$ subjects with single episode depression $(\mathrm{OR}=1.895 \%$ CI 1.3-2.3).

Overall association between family history and depression in probands

Probands with a lifetime diagnosis of MDD had a higher proportion of affected first-degree relative than probands without lifetime MDD (mean proportion of relatives affected 0.15 vs. 0.08 ). The odds ratio for a positive family history and lifetime diagnosis of MDD in the probands was 2.1 (95\% CI 1.9-2.4).

Associations between family loading and clinical characteristics of depression

In our main analyses we studied the effects of FLSD and gender on the clinical characteristics of depression in the probands. In Table 3 we present the unadjusted analyses (Table 3a), the analyses adjusted for the effects of potential confounders (age, education and number of first-degree relatives; Table $3 \mathrm{~b}$ ); and analyses adjusted for the effects of potential confounders and the effects of depression characteristics other than those expressed in the dependent variable (Table 3c).

From Table 3 it can be concluded that both FLSD and female gender predict depression in the probands. The similarity of the results presented in Table $3 \mathrm{a}$, b shows that the potential confounders including age, educational level have only small effects. Overall, a higher FLSD is associated with higher risk for depression in the probands. FLSD has significantly stronger associations with severe depression compared to mild depression (direct comparison: logistic regression analysis OR 4.8 95\% CI 2.5-9.1), recurrent depression compared to the single episode subtype (direct comparison: logistic regression analysis OR 3.0 95\% CI 1.7-5.3) and with early age of onset compared to late age of onset of depression (direct comparison: logistic regression analysis OR $2.895 \%$ CI 1.2-6.8).

Adjusting the analyses of the clinical characteristics with the strongest FLSD effects (severe depression, recurrent depression and depression with early onset) for the effects of the other MDD characteristics (Table 3c) resulted in smaller but still significant FLSD effects. So it can be concluded that FLSD has unique effects on severe, recurrent and early onset depression.

In a final set of analyses (data not shown) we did not observe significant effects of interactions between FLSD and gender on the depression phenotype characteristics (logistic regression analysis adjusting for the effects of potential confounders).

\section{Discussion}

Twin studies have demonstrated that genetic factors and unshared environmental factors play an important role in the aetiology of MDD. In the absence of contributions of shared environment, familial associations in depression largely reflect shared genetic variance [12, 20].

The present study is one of the few to study associations between familiality and phenotypic characteristics of 
depression in a large representative community study. A number of important conclusions can be drawn.

1. Associations between family history and lifetime history of depression are comparable to those of earlier studies in clinical patients.

2. A higher FLSD is associated with increased probability of lifetime depression diagnosis in the probands.

3. Family loading is associated with specific clinical characteristics of depression in the probands.

4. Effects of gender and family loading on depression in probands are largely additive.

1. The association between family history and lifetime depressive disorder diagnosis in the present study (OR $2.195 \%$ CI 1.9-2.4) is in agreement with the results of clinical studies. A recent meta-analysis reported an overall odds ratio of 2.84 (95\% CI 2.31-3.49) for the risk of depression among first-degree relatives of probands with depression compared to the risk in firstdegree relatives of subjects without a history of depression [36]. Two studies in this meta-analysis used unscreened controls [27, 37]. The odds ratios of these studies (2.2 and 2.3, respectively) match our results much more closely. Furthermore, depression morbidity in the first-degree relatives of depressed subjects and controls are highly comparable to those reported from clinical studies (15.0 vs. 15.2-21.0\% and 7.9 vs. $5.5-10.6 \%$ ). The degree of agreement is remarkable as there are substantial methodological differences between the studies included in the metaanalysis and the present study. First, the proband groups in the earlier studies [10, 27, 37, 39, 41] consisted mainly of clinical subjects. It has been suggested that for clinical patients, factors such as higher reliability of the clinical diagnosis and severity of depression will result in higher heritability estimates $[18,29]$. Second, the studies in the meta-analysis used direct interviews of relatives (the family study method; FSM) while in the present study the probands themselves reported the depression status of their relatives (family history method; FHM). Our findings confirm the results of two other population-based studies reporting odds ratios between 2.7 and 3.0 for depression in offspring of parents with a history of depression $[15,25]$.

2. The FLSD was created to measure the degree to which the proband's family is affected with depression. We found that a higher FLSD was associated with increased risk for depression and a higher prevalence of specific phenotypical characteristics like severity, recurrence and early age of onset of depression. So far, only a few studies have studied the effects of the proportion of affected relatives on the occurrence and phenotypical characteristics of depression. An early study by Gershon et al. [10] reported that the morbidity risk in offspring was considerably higher if both parents were ill: $74 \%$ with two affected parents versus $27 \%$ with only one parent affected. Lieb et al. [25] reported increased odds ratio's for depression in probands if two parents had suffered depression compared to one parent. However, this increase did not reach significance. Recently, Weissman et al. [42] reported significantly higher frequencies of psychopathology in grandchildren from families with two generations (grandparents and parents) of major depression compared to families with only affected grandparents. Evidence at the level of the genotype was reported by Joiner et al. [14]. Individuals with the s/s genotype of the serotonin 5-HTTLPR polymorphism, an important candidate gene for depression, had significantly more first-degree relatives with a history of depression than subjects with the $\mathrm{s} / \mathrm{l}$ or $1 / 1$ genotypes.

3. Family loading had strong and unique associations with recurrence, severity and early age of onset of depression in the probands. These findings are in agreement with those of earlier studies, most of which were based on the FSM. Recurrence is the subtype that has been found to be consistently associated with heritability both in family and in twin studies [11, 16, 19, 25, 29]. Severity of depression can be defined according to the nature of depressive symptoms or the level of impairment. A number of studies have reported stronger associations with familiality of depression in probands with a higher degree of impairment [11, 16, 19, 25, 29]. Leckman et al. [23] and Lyons et al. [26] reported more depression in relatives of subjects with more severe symptomatology of depression including the delusional and melancholic subtypes. Several authors reported significant associations between early age of onset and depression in relatives [25, 26, 28, 30, 40] others did not [19]. Although recurrence and early age of onset of depression are interrelated, these characteristics had independent and significant associations with the FLSD.

4. As expected, female gender was associated with a higher risk for depression in the probands. Gender effects on lifetime depression in the probands were additive to the effects of family loading in all the subtypes. There was no evidence of effects of interactions between gender and family loading. This finding is in agreement with other studies [31, 33] and suggests that the gender effect is largely unrelated to familial, or more specifically genetic factors.

A number of limitations have to be acknowledged. First, considering the large sample size of this study, it 
was not feasible to have direct interviews with first-degree relatives. Using the FHM we were able to collect complete information on all the 37,336 parents and siblings of the 7,076 probands, including relatives that had deceased. It has been shown that the FHM has limitations in sensitivity compared to direct information gathered in the FSM. [2, 3, 32]. For the present study, however, we showed that a single question considering family history has substantial agreement with the frequently used FHRDC diagnosis which, in turn, accorded strongly with a lifetime depression diagnosis, based on direct interviews of relatives.

Second, the use of the lifetime diagnosis of MDD has limitations. Foley et al. [8] classified its reliability as 'fair'. Reliability was higher in subjects reporting higher levels of depressive symptoms, more limitations, a higher number of episodes, longer illness duration and in subjects who looked for professional help. In a different study, Kendler et al. [18] reported a modest reliability of lifetime diagnosis of MDD. Reliability was predicted by number of depressive symptoms, treatment seeking, number of episodes and degree of impairment. Interestingly, the use of the more reliable results was accompanied by a dramatic increase of heritability: according to Kendler et al. [18] estimations rose from 40 to $70 \%$. Therefore, these measurement characteristics of the lifetime diagnosis of depression may contribute to the stronger familial associations of both the recurrent and the severe subtype of MDD in our study. Third, so-called 'projection bias' may have played a role. Several studies have shown that subjects with psychiatric disorders do more sensitively but less specifically report psychiatric illness in their relatives. [6, 21]. Finally, as both the FHM and lifetime depression diagnosis rely on recall and reporting of depression in relatives and oneself, respectively, it cannot be excluded that confounding may have played a role and may have influenced associations and morbidity risks to some extent.

In summary, this study showed that associations between family history and depression that have been frequently demonstrated in clinical samples do also apply to probands living in the community. Family loading, indexing the proportion of first degree relatives positive for depression, had independent effects on three separate clinical dimensions of depression in probands: severity, recurrence and early age of onset. As these clinical characteristics all do indicate increased disease burden, it can be concluded that family loading not only predicts risk for depression in probands living in the community, but also predicts increased disease burden in subjects who eventually become depressed. Finally, our finding that the effects of family loading and gender are largely additive suggests that these variables are to be considered as independent risk factors for depression.
Acknowledgments NEMESIS was supported by the Dutch Ministry of Health, Welfare and Sports (VWS).

Open Access This article is distributed under the terms of the Creative Commons Attribution Noncommercial License which permits any noncommercial use, distribution, and reproduction in any medium, provided the original author(s) and source are credited.

\section{References}

1. American Psychiatric Association (1987) Diagnostic and statistical manual, 3rd edn, revised. American Psychiatric Association, Washington DC

2. Andreasen NC, Endicott J, Spitzer RL, Winokur G (1977) The family history method using diagnostic criteria. Reliability and validity. Arch Gen Psychiatry 34:1229-1235

3. Andreasen NC, Rice J, Endicott J, Reich T, Coryell W (1986) The family history approach to diagnosis. How useful is it? Arch Gen Psychiatry 43:421-429

4. Bijl RV, Ravelli A, van Zessen G (1998) Prevalence of psychiatric disorder in the general population: results of The Netherlands Mental Health Survey and Incidence Study (NEMESIS). Soc Psychiatry Psychiatr Epidemiol 33:587-595

5. Bijl RV, van Zessen G, Ravelli A, de Rijk C, Langendoen Y (1998) The Netherlands Mental Health Survey and Incidence Study (NEMESIS): objectives and design. Soc Psychiatry Psychiatr Epidemiol 33:581-586

6. Chapman TF, Mannuzza S, Klein DF, Fyer AJ (1994) Effects of informant mental disorder on psychiatric family history data. Am J Psychiatry 151:574-579

7. Cottler LB, Robins LN, Grant BF, Blaine J, Towle LH, Wittchen HU, Sartorius N (1991) The CIDI-core substance abuse and dependence questions: cross-cultural and nosological issues. The WHO/ADAMHA field trial. Br J Psychiatry 159:653-658

8. Foley DL, Neale MC, Kendler KS (1998) Reliability of a lifetime history of major depression: implications for heritability and comorbidity. Psychol Med 28:857-870

9. Gardner MJ, Altman DG (1986) Confidence intervals rather than $\mathrm{P}$ values: estimation rather than hypothesis testing. Br Med J (Clin Res Ed) 292:746-750

10. Gershon ES, Hamovit J, Guroff JJ, Dibble E, Leckman JF, Sceery W, Targum SD, Nurnberger JI Jr, Goldin LR, Bunney WE Jr (1982) A family study of schizoaffective, bipolar I, bipolar II, unipolar, and normal control probands. Arch Gen Psychiatry 39:1157-1167

11. Gershon ES, Weissman MM, Guroff JJ, Prusoff BA, Leckman JF (1986) Validation of criteria for major depression through controlled family study. J Affect Disord 11:125-131

12. Glowinski AL, Madden PA, Bucholz KK, Lynskey MT, Heath AC (2003) Genetic epidemiology of self-reported lifetime DSMIV major depressive disorder in a population-based twin sample of female adolescents. J Child Psychol Psychiatry 44:988-996

13. Harrington R, Rutter M, Weissman M, Fudge H, Groothues C, Bredenkamp D, Pickles A, Rende R, Wickramaratne P (1997) Psychiatric disorders in the relatives of depressed probands. I. Comparison of prepubertal, adolescent and early adult onset cases. J Affect Disord 42:9-22

14. Joiner TE Jr, Johnson F, Soderstrom K, Brown JS (2003) Is there an association between serotonin transporter gene polymorphism and family history of depression? J Affect Disord 77:273-275

15. Kendler KS, Davis CG, Kessler RC (1997) The familial aggregation of common psychiatric and substance use disorders in the National Comorbidity Survey: a family history study. Br J Psychiatry $170: 541-548$ 
16. Kendler KS, Gardner CO, Prescott CA (1999) Clinical characteristics of major depression that predict risk of depression in relatives. Arch Gen Psychiatry 56:322-327

17. Kendler KS, Gatz M, Gardner CO, Pedersen NL (2005) Age at onset and familial risk for major depression in a Swedish national twin sample. Psychol Med 35:1573-1579

18. Kendler KS, Neale MC, Kessler RC, Heath AC, Eaves LJ (1993) The lifetime history of major depression in women. Reliability of diagnosis and heritability. Arch Gen Psychiatry 50:863-870

19. Kendler KS, Neale MC, Kessler RC, Heath AC, Eaves LJ (1994) The clinical characteristics of major depression as indices of the familial risk to illness. Br J Psychiatry 165:66-72

20. Kendler KS, Prescott CA (1999) A population-based twin study of lifetime major depression in men and women. Arch Gen Psychiatry 56:39-44

21. Kendler KS, Silberg JL, Neale MC, Kessler RC, Heath AC, Eaves LJ (1991) The family history method: whose psychiatric history is measured? Am J Psychiatry 148:1501-1504

22. Klein DN, Lewinsohn PM, Seeley JR, Rohde P (2001) A family study of major depressive disorder in a community sample of adolescents. Arch Gen Psychiatry 58:13-20

23. Leckman JF, Weissman MM, Prusoff BA, Caruso KA, Merikangas KR, Pauls DL, Kidd KK (1984) Subtypes of depression. Family study perspective. Arch Gen Psychiatry 41:833-838

24. Levinson DF, Zubenko GS, Crowe RR, DePaulo RJ, Scheftner WS, Weissman MM, Holmans P, Zubenko WN, Boutelle S, Murphy-Eberenz K, MacKinnon D, McInnis MG, Marta DH, Adams P, Sassoon S, Knowles JA, Thomas J, Chellis J (2003) Genetics of recurrent early-onset depression (GenRED): design and preliminary clinical characteristics of a repository sample for genetic linkage studies. Am J Med Genet B Neuropsychiatr Genet 119:118-130

25. Lieb R, Isensee B, Hofler M, Wittchen HU (2002) Parental depression and depression in offspring: evidence for familial characteristics and subtypes? J Psychiatr Res 36:237-246

26. Lyons MJ, Eisen SA, Goldberg J, True W, Lin N, Meyer JM, Toomey R, Faraone SV, Merla-Ramos M, Tsuang MT (1998) A registry-based twin study of depression in men. Arch Gen Psychiatry $55: 468-472$

27. Maier W, Lichtermann D, Minges J, Hallmayer J, Heun R, Benkert O, Levinson DF (1993) Continuity and discontinuity of affective disorders and schizophrenia. Results of a controlled family study. Arch Gen Psychiatry 50:871-883

28. McGuffin P, Katz R, Bebbington P (1987) Hazard, heredity and depression. A family study. J Psychiatr Res 21:365-375

29. McGuffin P, Katz R, Watkins S, Rutherford J (1996) A hospitalbased twin register of the heritability of DSM-IV unipolar depression. Arch Gen Psychiatry 53:129-136

30. Mendlewicz J, Baron M (1981) Morbidity risks in subtypes of unipolar depressive illness: differences between early and late onset forms. Br J Psychiatry 139:463-466

31. Merikangas KR, Weissman MM, Pauls DL (1985) Genetic factors in the sex ratio of major depression. Psychol Med 15:63-69

32. Orvaschel H, Thompson WD, Belanger A, Prusoff BA, Kidd KK (1982) Comparison of the family history method to direct interview. Factors affecting the diagnosis of depression. J Affect Disord 4:49-59

33. Piccinelli M, Wilkinson G (2000) Gender differences in depression. Critical review. Br J Psychiatry 177:486-92.:486-492

34. Robins LN, Wing J, Wittchen HU, Helzer JE, Babor TF, Burke J, Farmer A, Jablenski A, Pickens R, Regier DA (1988) The composite international diagnostic interview. An epidemiologic Instrument suitable for use in conjunction with different diagnostic systems and in different cultures. Arch Gen Psychiatry 45:1069-1077

35. Semler G, Von Cranach M, Wittchen H-U (1987) Comparison between the composite international diagnostic interview and the present state examination. Report to the WHO/ADAMHA Task Force on Instrument Development. WHO, Geneva

36. Sullivan PF, Neale MC, Kendler KS (2000) Genetic epidemiology of major depression: review and meta-analysis. Am J Psychiatry 157:1552-1562

37. Tsuang MT, Winokur G, Crowe RR (1980) Morbidity risks of schizophrenia and affective disorders among first degree relatives of patients with schizophrenia, mania, depression and surgical conditions. Br J Psychiatry 137:497-504

38. Weissman MM, Gammon GD, John K, Merikangas KR, Warner V, Prusoff BA, Sholomskas D (1987) Children of depressed parents. Increased psychopathology and early onset of major depression. Arch Gen Psychiatry 44:847-853

39. Weissman MM, Gershon ES, Kidd KK, Prusoff BA, Leckman JF, Dibble E, Hamovit J, Thompson WD, Pauls DL, Guroff JJ (1984) Psychiatric disorders in the relatives of probands with affective disorders. The Yale University-National Institute of Mental Health Collaborative Study. Arch Gen Psychiatry 41:13-21

40. Weissman MM, Merikangas KR, Wickramaratne P, Kidd KK, Prusoff BA, Leckman JF, Pauls DL (1986) Understanding the clinical heterogeneity of major depression using family data. Arch Gen Psychiatry 43:430-434

41. Weissman MM, Wickramaratne P, Adams PB, Lish JD, Horwath E, Charney D, Woods SW, Leeman E, Frosch E (1993) The relationship between panic disorder and major depression. A new family study. Arch Gen Psychiatry 50:767-780

42. Weissman MM, Wickramaratne P, Nomura Y, Warner V, Verdeli H, Pilowsky DJ, Grillon C, Bruder G (2005) Families at high and low risk for depression: a 3-generation study. Arch Gen Psychiatry 62:29-36

43. Wittchen HU (1994) Reliability and validity studies of the WHO-composite international diagnostic interview (CIDI): a critical review. J Psychiatr Res 28:57-84

44. World Health Organization (1990) Composite international diagnostic interview (CIDI), Version 1.0. World Health Organization, Geneva

45. Zubenko GS, Maher B, Hughes HBIII, Zubenko WN, Stiffler JS, Kaplan BB, Marazita ML (2003) Genome-wide linkage survey for genetic loci that influence the development of depressive disorders in families with recurrent, early-onset, major depression. Am J Med Genet B Neuropsychiatr Genet 123:1-18 